\title{
A new case management concept to decrease the rehospitalisation rate in heurischemic
}

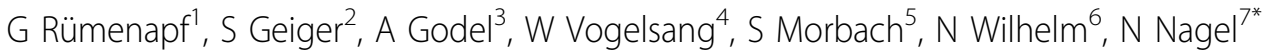 \\ From International Conference on Prevention \& Infection Control (ICPIC 2011) \\ Geneva, Switzerland. 29 June - 2 July 2011
}

\section{Introduction / objectives}

The treatment of patients suffering from the neuroischemic diabetic foot syndrome (DFS) comprises arterial revascularization (e.g. below-knee bypass surgery), minor amputations, debridements, as well as long-term specialized wound care. Following premature discharge to the homecare sector, the quality of postoperative care is often inadequate. Many patients are readmitted. We studied the influence of a trans-sectoral case management (CM), ensuring outpatient care according to our clinical standards, on the readmission rate, length of hospital stay (LOS) and the hospital's costs/benefit situation.

\section{Methods}

DFS patients after implementation of the CM (Case Management Group (CMG); n = 202; 2007-2008) were compared with a historic control group (HCG; $\mathrm{n}=190$; 2005-2006). All patients had high maintenance foot wounds as well as healing incisional wounds following bypass surgery. Both groups were matched for the principal diagnosis, a patients clinical complexity level (PCCL) of 4, and G-DRG-related flat rate. From the 202 CMG patients evaluated, 54 received long-term transsectoral care by the CM.

\section{Results}

The rehospitalization rate in the CMG was significantly reduced versus the HCG (9,8 \% vs.16,7\%; $\mathrm{p}=0,041)$. The reduction of the revolving door effect in the CMG significantly improved the costs/revenue situation for the hospital. The LOS was unchanged.

${ }^{7}$ Medical Scientific Affairs OPM, B. Braun Melsungen AG, Melsungen, Germany

Full list of author information is available at the end of the article

\section{Conclusion}

The implementation of a hospital-based trans-sectoral CM significantly reduces the rehospitalization rate in patients with neuroischemic DFS requiring bypass surgery. Hospital economics are improved.

\section{Disclosure of interest}

None declared.

\section{Author details}

${ }^{1}$ Clinic for Vascular Surgery, Diakonissen-Stiftungs-Krankenhaus Speyer, Speyer, Germany. ${ }^{2}$ Case Management, Diakonissen-Stiftungs-Krankenhaus Speyer, Speyer, Germany. ${ }^{3}$ Medical Controlling, Diakonissen-StiftungsKrankenhaus Speyer, Speyer, Germany. ${ }^{4} \mathrm{CEO}$, Diakonissen-StiftungsKrankenhaus Speyer, Speyer, Germany. ${ }^{5}$ Dept. Of Diabetology and Angiology, Marienkrankenhaus Soest, Soest, Germany. ${ }^{6}$ Konzeptmanagement, B. Braun Melsungen AG, Melsungen, Germany. ${ }^{7}$ Medical Scientific Affairs OPM, B. Braun Melsungen AG, Melsungen, Germany.

Published: 29 June 2011

doi:10.1186/1753-6561-5-S6-P326

Cite this article as: Rümenapf et al:: A new case management concept to decrease the rehospitalisation rate in heurischemic. BMC Proceedings 2011 5(Suppl 6):P326.

Submit your next manuscript to BioMed Central and take full advantage of:

- Convenient online submission

- Thorough peer review

- No space constraints or color figure charges

- Immediate publication on acceptance

- Inclusion in PubMed, CAS, Scopus and Google Scholar

- Research which is freely available for redistribution

\section{() Biomed Central}

